This article has been published in:

The Palgrave Handbook of Linguistic (Im)politeness. Jonathan Culpeper, Michael Haugh and Dániel Z.

Kádár (eds.). London: Palgrave Macmillan, 2017, 287-322.

This extract is taken from the author's original manuscript and has not been edited. The definitive, published, version of record is available here: https://link.springer.com/chapter/10.1057\%2F978-1-13737508-7 12. Reproduced with permission of Palgrave Macmillan.

If you want to quote from this document, please consult the page numbers in the right hand margins.

\title{
(Im)politeness and emotion
}

\author{
Andreas Langlotz and Miriam A. Locher
}

\section{Introduction}

This chapter explores the interconnectedness of emotions with (im)politeness from a theoretical and methodological perspective. Consider the following paraphrased examples, which all contain potentially face-challenging situations:

(1) A wife asks her husband to open a window for her while both are guests at a dinner party in a relative's house and the hostess is in a different room. This causes irritation in his wife. The husband, while acknowledging that the temperature is hot and that his wife has legitimate claims to get the window opened, first refuses to comply by referring to the host's rights at granting permission to open a window in her own house. Once the host's consent is won, he opens the window. (See Locher 2004, for a detailed discussion.)

(2) Commentators of online newspaper articles often attack each other ad hominem rather than concentrating on a factual discussion. These face-attacks are loaded with emotionally charged vocabulary and often result in further rounds of face-aggravating behaviour. (For examples of English newspapers see, e.g. Neurauter-Kessels 2013; Langlotz and Locher 2012.)

(3) An interactant goes to a tourist office to enquire about accommodation. The interaction with the clerk proceeds 'as usual' and is not particularly noteworthy with respect to faceenhancing or face-challenging behaviour. Instead, both interactants have established a face-maintaining stance that allows the interaction to run smoothly so that the expectations of both interactants are met. (See Langlotz 2015, for a detailed discussion.) 
In all three examples we see human beings engaged in interaction who use language to achieve their aims. We argue that the examples all contain emotional, relational and socionormative elements. In (1) we witness the negotiation of rights and obligations of husbands, wives and hosts. Not complying with expectations about rights, or fulfilling rights, will trigger negative and positive emotions that influence the continuation of the exchange. In (2), we encounter conflictual behaviour, which triggers defence mechanisms that are emotionally loaded. In (3), we find a non-conflictual encounter, which, however is an interactional achievement in itself since both participants adhere to norms of what is expected of clerk and client in this particular encounter. Even here, we argue, emotions play a role. Furthermore, all examples serve as illustrations of how acquired knowledge of sociality and the connected sociocultural norms shape interactions and relationships. In this chapter, we will focus on emotions within interpersonal pragmatics with the aim to establish their role in the complex interplay of human interaction.

As the study of emotions is a fundamental concern for studying humanity, it is not surprising that many scholarly disciplines have dedicated considerable efforts to theorising emotions. Giving a comprehensive overview of this field from philosophy to cognitive science is beyond the scope of this chapter (see Turner and Stets 2005; Turner 2007). Instead, we aim at touching upon important research strands throughout the chapter to establish the research interface that is fruitful for (im)politeness research and to outline better what we understand by emotions. In Sect. 2, we provide a schematic overview of systemic components involved in emotion. By means of this skeletal system we will situate central approaches to emotion and outline the position of interpersonal pragmatics relative to them. On the basis of this general overview, we then review contributions within the (im)politeness literature that have worked on emotions (Sect. 3). Since this discussion does not present a unified picture, we will use this literature review as a springboard to elaborate on three concerns that the research raises (Sect. 4): Cognition and emotions, sociality and emotions, and the communicative observables of emotions. How these fundamental links between emotion and interpersonal pragmatics pan out will then be illustrated by drawing on examples of interaction in Sect. 5. Finally, we offer concluding remarks and suggestions for further research paths in Sect. 6 .

\section{The fundamental links between emotion and interpersonal pragmatics}

The three scenarios described in the introduction may not have left you cold. While reading them, you may have shown emphatic or sympathetic reactions and felt some of the emotional states that the participants to these situations might have experienced themselves. ${ }^{1}$ Thus, although being absent to these situations the human imaginary power of thinking about possible experiential contexts holds the latent potential for triggering emotions associated with them. This informal insight points to the central role of emotions

\footnotetext{
${ }^{1}$ Note that we use a broad notion of emotion that also includes concepts such as affect and feeling. A substantial definition follows below. Other studies have differentiated them (for an overview see Langlotz and Soltysik Monnet 2014).
} 
in human and non-human life: they regulate the relationship of an experiencer to a given environment and mediate his/her/its orientation towards it (Damasio 1999, 2003). Emotions such as happiness, anger, love, disgust, embarrassment, shame or guilt can make us orient positively towards a given object, organism or person and approach them, or they can make us sense more negative feelings and cause us to shun away from them. Based on their emotional reactions, agents may thus perform a variety of (re)actions towards the environment ranging from destructive aggression to great happiness. This highly simplified system consisting of five fundamental components is illustrated by the bold terms in Fig. 12.1.

Neurobiological research shows that basic ways of emoting can already be found in basic organisms such as Aplysia californica, a sea snail, which emits black ink when being molested (Damasio 1999, p. 70). With regard to the components (1)-(5), human beings are, of course, much more complex agents than the mollusc.

(1) Extending their physiology (1a), human organisms have brains designed for complex cognitive capacities, including conceptualisation, memorisation, planning and decision-making (1b).

(2) Humans are social beings living in complex physical (2a) and social environments (2b) that are shaped through sociocultural practices (2c). These practices are bound to social norms and conventions. Moreover, humans are highly conscious of themselves. To some extent, they can conceptualise their inner-psychological states to make them become part of their worlds of direct experience (2d).

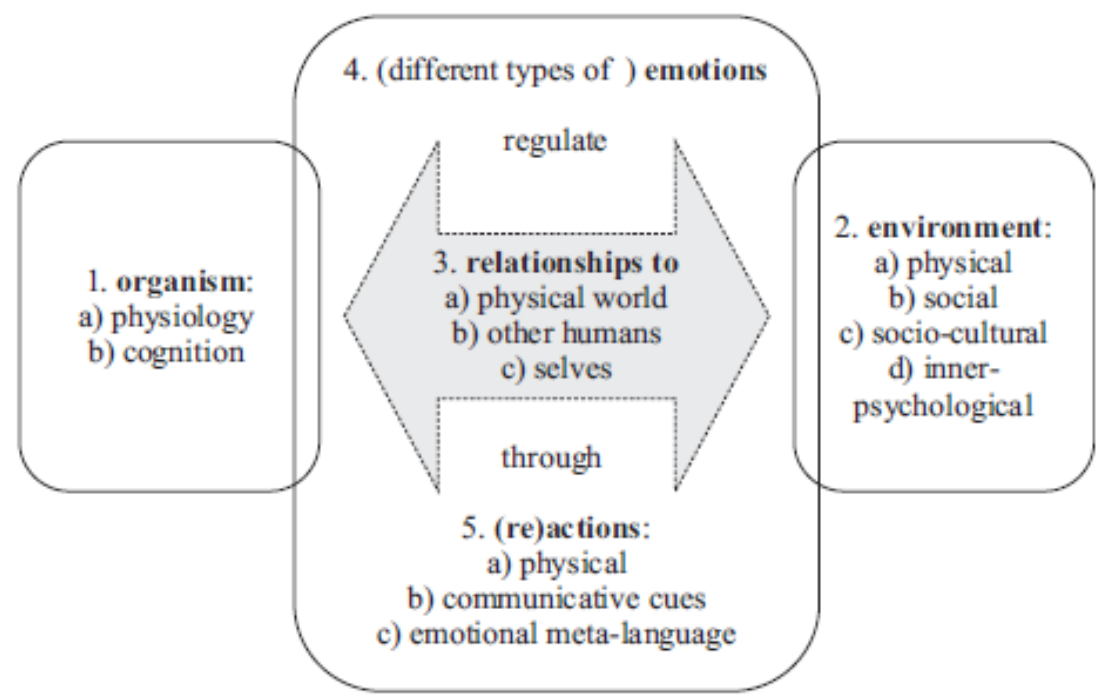

Fig.12.1. Emotions as regulators of relationship between organism and environment.

(3) Due to (2b) the most important connections between humans and their environments consists in social relationships (3b) ranging from dyadic engagements to differentiated roles within groups and societies. An individual's position in his/her social environment is defined through degrees of status/power, familiarity and duration (short to long-term engagements) (Langlotz 2015). Having concepts of their own selves and their own feelings (3c), 
humans also establish relationships to themselves and engage in identity construction.

(4) Due to the complexity of their environments and social relationships, human beings possess a very broad range of emotions to regulate their behaviours (see, e.g. Plutchik 2003).

(5) In their (re)actions, humans are not restricted to a repertoire of physical responses (5a). Being highly communicative beings and possessing the symbolic power of language, they can express and also describe emotions through an array of non-verbal and verbal cues (5b). Moreover, they may use language to conceptualise emotional states, to describe them and to talk about them through meta-comments (5c).

Several different approaches to and definitions of the concept of emotion exist. However, still 'there is little consensus on what emotion is or is not' (Barrett 1998, p. v, quoted in Schwarz-Friesel 2007, p. 43). In our view, this is mainly due to the differing ways in which different approaches to emotion have analysed, researched and interpreted the complex interaction between the components and subcomponents in (1)-(5).

In neuropsychology the main focus has been on the connections between (1a), (2) and (4), i.e. on the neurophysiological status of emotions as part of the human 'homeostasis machine' (Damasio 1999, p. 55; see also Damasio 1994, 2003, 2004; James 1884; LeDoux 1998). While the precise mechanisms underlying emotions as physiological reactions are not of central interest here, it is important to emphasise that these approaches underline the fundamental role for emotions in the architecture of human psychology and behaviour. Importantly, they show that rational thinking is not possible without the evaluative influence of emotional components and that higher-level cognitive capacities seem to be fundamentally shaped by these lower-level somatic survival mechanisms (Damasio 2003, pp. 145-9).

In cognitive psychology, the complex interrelation between the environment (2), emotions (4) and cognition (1b) in the intelligent human regulation of organismenvironment interaction has been of central interest. Most importantly, appraisal theory proposes that emotions are triggered by the cognitive interpretation of a stimulus event (Frijda 1986; Lazarus 1991; Scherer et al. 2001). These evaluations (positive vs. negative) then lead to emotional arousal. Unlike neuropsychology, appraisal theory thus stresses the importance of cognitive interpretations (1b) of the world of experience over the prior presence of physiological arousal (1a).

Sociological theories of emotion have been primarily concerned with the links between (2b), (3), and (4), i.e. how emotions are linked to patterns of social organisation and how they are involved in relationship building (3b). Among others, dramaturgical theories stand in a Goffmanian tradition and are interested in how 'individuals make dramatic presentations and engage in strategic actions directed by a cultural script' (Turner and Stets 2005, p. 26). In this tradition we find a strong interest in sociocultural norms (2c) and strategic orientations towards them, including emotional impression management 
(Goffman 1967; Hochschild 1979, 1983). Symbolic interactionist theories place their central focus on how individuals seek to confirm their self-conceptions and identities (2d), i.e. they wish to verify the emotional relationship to themselves in interaction with others (3c):

When self is verified by others responding to self in a manner that is consistent with self's own view, the person experiences positive emotions, such as pride and satisfaction. When self is not confirmed, however, the incongruity between self-directed behavior and the responses of others generates negative emotions such as distress, anxiety, anger, shame, and guilt. (Turner and Stets 2005, p. 29)

Finally, social constructionist approaches, as for example proposed by Harré (1986), have opposed biological and psychological theories, claiming that emotions are not empirically measurable objects of analysis but socially constructed entities that are highly culture specific. Most importantly, they propose that culture-specific ways of speaking about emotions (5c) shape culture-specific ideologies of what they are. A similar approach is taken in anthropological studies, which are interested in how complex culture-specific forms of performing and speaking about emotions and emotionality (5a)-(5c) shape emotions (4), social and cultural environments (2b, 2c), relationships (3b) and culturespecific identities (3c) (Wilce 2009; Wierzbicka 1994).

In communication studies, (1b), (2) and (3) are also highly important. However, unlike the previously mentioned approaches, communication studies start from (5b) and are interested in how emotional communicative cues are used to express emotions in different types of communication (e.g. family, marital, conflict, business or intercultural communication) and how these forms of emotional communication influence relationships (3b) and self-concepts $(3 \mathrm{c})$ within such contexts. Communication studies are also interested in how emotional communication can be managed to improve communication between interactants.

With regard to language-related fields of study distinct from linguistic pragmatics and (im)politeness research, emphasis has primarily been on the verbal component of (5b). The Aristotelian tradition of rhetoric has focused on how verbal pathos can be used to influence the orators' relationship to their audience (3b) and thus use language to cause changes in (2b) or (2c) (see Micheli 2008). In literary and cultural studies, different styles of articulating emotionality in combination with the question of how such styles shape ideologies and conceptions of what emotions (4) are have been of central interest (Langlotz and Soltysik Monnet 2014). In linguistics, the structure of verbalising the emotional component of experience has been of recent interest (Bednarek 2008; Foolen 2012; Oster 2012; Schwarz-Friesel 2007).

Where can interpersonal pragmatics be positioned within this skeletal overview? Interpersonal pragmatics is centrally interested in how interactants use language to construct, negotiate, maintain, challenge and change social relationships. With regard to Fig. 12.1, the use of emotional cues (5b) as well 
as emotional meta-comments $(5 c)$ for the emotional regulation of interpersonal relationships (3b) thus constitutes the central object of analysis with regard to linking emotions to (im)politeness (see Langlotz and Locher 2013, p. 99, Fig. 2). However, as the previous literature review has shown, we should also be strongly interested in the impact of emotions on cognitive processes of interpretation and the impact of cognition on emotional reactions (1b) (Locher and Langlotz 2008; Culpeper 2010; Culpeper et al. 2014). In addition, the construction of relationships must always be understood relative to sociocultural environments and interactional contexts in which they take place (2c). Finally, as the idea of 'face' is linked to the conceptualisation of the self (3c) and corresponding inner-psychological feeling states $(2 \mathrm{~d})$, these dimensions involved in activating situated identities in relational work also play a central role in the complex system of connections between emotion and the management of (im)politeness in relational work (Langlotz 2010). This leads us to a short overview of research foci on emotions and (im)politeness in (im)politeness research.

\section{Emotions and (im)politeness in (im)politeness research}

It would be a gross misrepresentation to say that the importance of the role of emotions and feelings has not been pointed to within (im)politeness research. However, many of the most popular works on politeness mention emotions only in passing and do not discuss their influence or role within interpersonal pragmatics in great detail. For example, Brown and Levinson $(1987, \mathrm{pp} .67,68)$ primarily mention the display of emotions or lack of control of emotions as potentially face threatening and refer to the 'communication of affect' (display rules ${ }^{2}$ and emotional stance) when claiming that '[i]nsofar as the display of affect is socially constructed, with cultural and situational expectations about what and how feelings should be displayed, work here links directly with our discussions of [face-threatening acts, positive politeness strategies, and cultural ethos]' (Brown and Levinson 1987, p. 28). They maintain that studying how 'appropriate levels of affect' are conveyed is of concern for linguists studying politeness. Leech's Pragmatics of Politeness (2014, pp. 4-9) does not include mention of the involvement of emotions

in the assessment of politeness as one of his proposed 'eight characteristics of politeness'

(see also Leech 1983), but does refer to the role of affect and familiarity as being part of Brown and Levinson's D variable (horizontal distance) in his discussion of requests (p. 139). Kienpointner (2008, pp. 246-7) further argues that, along with proposing that affect and familiarity in themselves are important factors when assessing the weightiness of an imposition, the variables power and distance proposed by Brown and Levinson (1987) also contain elements of emotions. This is because the relational history of interactants and

\footnotetext{
2 The concept of emotional display rule was proposed by Ekman and Friesen (1969) with regard to the communicative management of facial expressions. Communicators may change the expressive surface of their emotional states by simulating, inhibiting, intensifying, de-intensifying or masking their actual emotions in order to follow culture-specific norms of appropriate emotional display (see Sect. 4.2; Langlotz and Locher 2013).
} 
meeting face-concerns against the backdrop of local expectations about roles in interaction have a fundamentally emotional component (see, e.g. Arndt and Janney 1985). Screening the literature, we also find a number of contributions that study metacomments about relational work that contain emotional assessments and emotional cues within interaction in order to gain a better understanding of breaches and maintenance of norms (for examples in this tradition, see Chang and Haugh 2011; Culpeper 2010, 2011; Culpeper et al. 2014; Kienpointner 2008; Langlotz and Locher 2012, 2013; Locher and Langlotz 2008; Locher and Koenig 2014; Ruhi 2009; Ruhi and Isik-Güler 2007; SpencerOatey 2011).

It is apparent, then, that the literature refers to emotions, on the one hand, as being displayed and conveyed, and, on the other hand, as being taken into account when choosing and assessing relational strategies. In this way they are thus part of creating and processing relational meaning. Consider what Culpeper (2011, p. 60) argues in his work on impoliteness:

Displaying emotions such as contempt or anger has nothing in itself to do with impoliteness. However, somebody displaying great contempt for and anger at someone and doing so publicly may be judged [...] to have acted in an inappropriately and unfairly hurtful way [...], causing an emotional reaction such as embarrassment or anger [...]. (Culpeper 2011, p. 60)

Culpeper here refers both to the explicit conveying of emotions, i.e. making manifest to an interlocutor how the speaker feels, and to the reactions to this display, which are emotional in turn. The former concerns the study of a surface structure, while the second is more fundamentally concerned with theorising how emotions cognitively contribute to relational understandings. Culpeper (2011, pp. 60-61) draws on Haidt's (2003) work on moral emotions and especially elaborates on the link between face and emotions (Goffman 1967). The latter is also of particular concern in Spencer-Oatey's (2005) work. In her discussion of rapport management (Spencer-Oatey 2005, 2011), she shows that 'emotional reactions' of the speaker and addressee play a fundamental role in the negotiation of face concerns (see Fig. 12.2). 


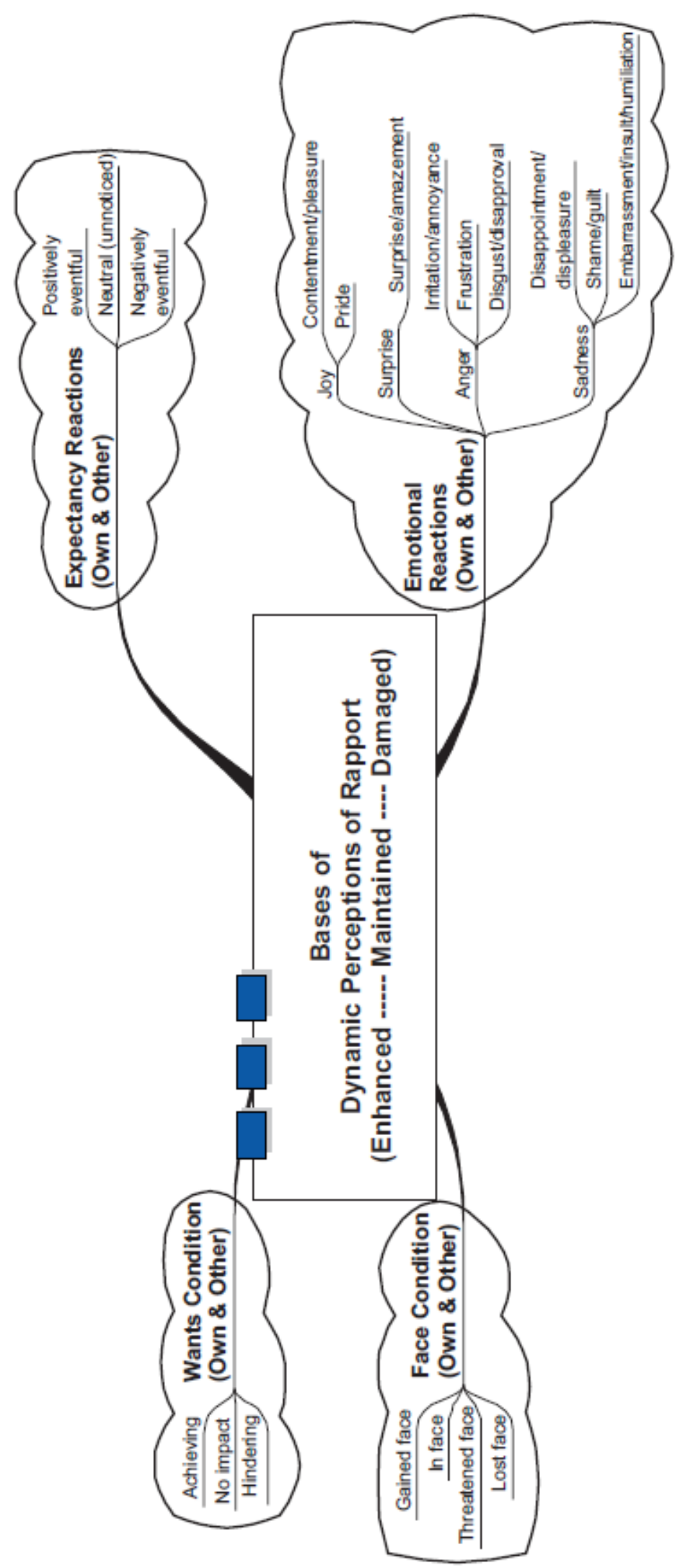

Fig. 12.2. 'The base of dynamic perceptions of rapport' (from: Spencer-Oatey 2005, p. 116).

This is true for expectancy reactions (positively, neutral or negatively eventful) and in what 296 she terms 'emotional reactions' (joy, surprise, anger, sadness and their subgroups) in the $\downarrow$ dynamic perception of rapport. 
In Garcés-Conejos Blitvich's (2013) discussion of the connection of the concept of face and identity, she argues that both concepts should be linked to emotions (see also Ruhi 2007, pp. 140-1, 2009, p. 170):

Identity verification is according to Burke and Stets (2009) a central process in identity construction [...]. Identities can be verified, partially verified or not verified by other agents. Verification/non-verification is associated with very positive/negative emotions. These emotions, which are usually associated with face, as Spencer-Oatey argues (2007: 644 see above), are also crucially connected with identity. Those positive/negative emotions associated with the maintenance/enhancement/threat to face can then be associated as well with the verification/non-verification of an identity. Thus, (im)politeness evaluations can be tied to identity, not just to face. After all, a way to get people very upset is to tell them (explicitly or implicitly) that they are not who they claim to be or think they are. A person may feel very offended if somebody whom $\mathrm{s} /$ he considers a friend introduces him/her to others simply as a colleague or an acquaintance. Positive feelings, traditionally associated with politeness assessments, may result when a friend tells you that you are more like a sister than a friend to her. In both cases, (im)politeness may ensue as a result of the construction of a given social identity for an individual. (Garcés-Conejos Blitvich 2013, p. 17)

Identity construction, in this line of reasoning, is the outcome of relational work/facework/rapport management that entails the assessment of whether expectations about emotional orientation and fulfilling of roles are met in situ (see also Locher 2008).

When Haugh et al. $(2013$, p. 4) assess the research scope of interpersonal pragmatics, they identify three areas of interest: (1) interpersonal relations; (2) interpersonal attitudes and emotions; and (3) interpersonal evaluations (see also Culpeper and Haugh 2014, p. 197):

(1) 'The primary area of concern in interpersonal pragmatics is naturally interpersonal relations, which encompasses "mutual social connections amongst people that are mediated by interaction, including power, intimacy, roles, rights and obligations" (Culpeper and Haugh [2014, p. 197]).' (emphasis in original)

(2) '[T]he area of interpersonal attitudes, which encompasses "perspectives, usually value-laden and emotionally charged, on others that are mediated by interaction, including generosity, sympathy, like/dislike, disgust, fear and anger" (Culpeper and Haugh [2014, p. 197]),' and the 'area of

interpersonal emotions, which encompasses embodied feelings or state-of mind often characterised by participants as "irrational and subjective, unconscious rather than deliberate [and] genuine rather than artificial” (Edwards 1999: 273).' (emphasis in original)

(3) The area of 'interpersonal evaluations, which involve "appraisals or assessment of persons, or our relationships with those persons, which influence the way we think and feel about those persons and relationships, and consequently sometimes what we do" (Kádár and Haugh 2013: 61).' ${ }^{3}$ (emphasis in original)

\footnotetext{
${ }^{3}$ In Culpeper and Haugh (2014, pp. 197-8), the authors subsume interpersonal emotions and interpersonal evaluations within interpersonal attitudes.
} 
While in area (2) emotions are explicitly mentioned, (1) and (3) also involve emotions, since they are part of relationship building and appraisals are cognitively linked to emotional reactions. As the authors point out, these three levels are in fact interrelated and 'in practice the analysis of face and (im)politeness is often necessarily intertwined' (Haugh et al. 2013, p. 4). The same comment is valid for emotions as they play a role on all three levels, too.

What we take from this overview is that we have to be especially aware of what level of study we are referring to when making claims about emotions and their roles within interpersonal pragmatics. We propose three areas that can be disentangled to better understand the nature of emotions: ${ }^{4}$

- Cognition and emotions: What are emotions and what role do they play in cognitive processes of sense-making?

- Sociality and emotions: What is the connection of emotions and interpersonal pragmatics? What is at stake when emotions come into play (e.g. identity construction and relationship negotiations)?

- Communicative observables of emotions: While the discussion of the first two areas is of a fundamental, theoretical nature, analysts in the field of interpersonal pragmatics only have direct access to what is observable in interaction (e.g. emotion display rules, emotion meta-comments, words expressing emotional connotations; visible somatic states, etc.). What does the literature offer us as tools to describe surface structures of emotional stance for a systematic description?

We will flesh these areas out in Sect. 4 by drawing on further literature on language and emotions and other disciplines working on emotions. How these levels are connected will be illustrated in Sect. 5 .

\section{The links of emotions to cognition, sociality and communicative observables}

Before we elaborate on the three areas raised in the previous section, we need to posit that emotions and emotionality cannot be restricted to internal physiological states of anger, fear, etc. Instead, they are multicomponential 'syndromes' that, according to Plutchik (2003, pp. 108-11), derive their conceptual complexity from three definitional perspectives: (a) structural, (b) sequential and (c) derivational. These distinctions are useful in better understanding the positions on emotions taken within and across the three areas outlined below.

The structural perspective on emotions tries to compare different types of emotions and their relationship to one another. For instance, according to Plutchik's (1962, 1980,

\footnotetext{
${ }^{4}$ Arndt and Janney (1985, p. 286) propose to study '(1) emotions generally, (2) how they are expressed, suppressed or otherwise modified in face-to-face speech [our third point], and (3) how emotive expression affects transitory interpersonal relationships [this is part of our second point].' Arndt and Janney (1985, p. 282) also argue that ' $[t]$ he domain of relevance in studying or teaching politeness, we suggest, is emotive communication - the communication of transitory attitudes, feelings and other affective states'. They thus clearly highlight the importance of emotions within any (im)politeness framework.
} 
2003) famous multidimensional structural model, emotions can be metaphorically compared to a spectrum of colours and arranged according to an emotional 'colourwheel'. The wheel contains eight basic emotions (anger, anticipation, joy, trust, fear, surprise, sadness, disgust) that have a certain similarity and polarity. For instance, joy is more similar to trust and anticipation than to fear and it stands in polar opposition to sadness. Like colours, these emotions can also vary along a range of intensity. Thus, joy ranges from serenity to ecstasy, while sadness lies on a continuum between pensiveness and grief. Finally, the basic emotions with their different degrees of intensity can also be blended, which results in secondary and tertiary emotions. According to Plutchik (2003, p. 105), contempt can be seen as a blend between the primary emotions disgust and anger. A similar classificatory grid for the structural dimension of emotions is offered by SchwarzFriesel (2007, see Table 12.1).

Table 12.1. Classificatory grid for emotion categories, based on Schwarz-Friesel (2007, Ch. 3.3, see also Langlotz and Locher 2013, p. 90).

\begin{tabular}{ll}
\hline Emotion: & \\
\hline A. Type and function: & emotion categories \\
B. Quality: & positive vs. negative evaluation \\
C. Intensity: & strong - weak continuum \\
D. Duration: & permanent vs. temporary \\
\hline
\end{tabular}

It is important to emphasise that such structural models have been severely criticised in anthropological, anthropological linguistic and social constructionist research (see, e.g. Harré 1986; Wierzbicka 1994). These researchers claim that different 'structural' emotion categories must be seen as highly culture specific rather than universal. It is, however, beyond the scope of this chapter to elaborate on this controversy more profoundly.

From a sequential perspective on emotions, it is not the structural distinctions between different emotion types that are of interest, but how emotions are part of complex behavioural processes. Every type of emotion, as classified from a structural perspective, can be seen to establish a complex behavioural sequence, which turns emotions into intricately distributed and dynamic phenomena. For example, the emotion 'contempt' involves the complex sequence of seeing or experiencing the behaviour or actions of a person, evaluating these actions as immoral, despicable or inappropriate, activating a corresponding physiological state of contempt, leading to the potential overt behaviour of a sneer or snub and avoiding him or her. Often such action tendencies can also be regulated. For instance, a politician may shake hands with a competitor from a different party despite wishing to dodge them. In accord with Planalp (1999, pp. 11-34; see also Scherer 1984), we can thus present the following sequential model for the emotional process of developing contempt for a person who speaks, for example, against the protection of sharks in Western Australia ${ }^{5}$ in Table 12.2 (see also Langlotz and Locher 2012, p. 1595).

\footnotetext{
${ }^{5}$ This example was inspired by an article in a Swiss online newspaper (http://bazonline.ch/panorama/
} 
It is important to note that from the linguistic perspective of interpersonal pragmatics, action tendencies as in column 4 in Table 12.2 comprise all the communicative dimensions of expressing and describing emotions $5 \mathrm{a}-\mathrm{c}$ in

Table 12.2. Sequential model of the emotional processes for 'contempt'.

\begin{tabular}{lllll}
\hline 1 & 2 & 3 & 4 & 5 \\
\hline $\begin{array}{l}\text { Stimuli } \\
\text { (object, event) }\end{array}$ & Appraisal & Physiological & Action & Regulation \\
(enfender shows & Interpretation of & Potential & Avoid the & Keep one's \\
a special & this statement & reactions & person, give & calm, enter \\
behaviour, e.g. & as immoral or & related to & him/her a & into a debate \\
he/she says: 'I & inappropriate & the basic & snort, tell him/ & about animals \\
think that all & & emotion of & her what one & rights, etc. \\
killer sharks & & disgust & thinks of such & \\
should be & & (bodily & attitudes & \\
hunted down' & & symptoms & towards & \\
& & of repulsion) & animals & \\
\hline
\end{tabular}

Fig. 12.1. Thus, stimuli for emotions and the reactions to these stimuli in human affairs are 300 communicative in many cases and involve negative and positive appraisals within the $\downarrow$ communicative situation (see Culpeper 2010).

The derivational perspective on emotions (Plutchik 2003, pp. 108-11) claims that emotions are part of derivational processes on phylogenetic, ontogenetic as well as psychological levels. The human sneer can be seen to be a phylogenetic derivative of the wolfish snarl (Darwin 1872). Similarly, emotional patterns that are part of baby-parent interaction can be reactivated later for adult-adult interaction. For instance, baby talk is often part of lovers' talk. Finally, personality traits and psychological disorders are also derived from more basic emotional states. Thus, a timid personality is based on fear and may lead to dependent-avoidant disorders.

These three perspectives on emotions play a role in debates and controversies that also reverberate for discussions concerning the link between emotions and (im)politeness. We can now turn to a more detailed discussion of the links between cognition and emotions, sociality and emotions, and their communicative observables as distilled from the literature review above and relate them to research interests in interpersonal pragmatics.

\subsection{Emotions and cognition}

In our view, the link between emotion and cognition must be regarded from two different perspectives: (a) the fundamental links between emotion and cognition in emotional processes and (b) the role of cognition for framing expectations about appropriate behaviours in a specific situation. These connections between emotion and

vermischtes/Australien-macht-Jagd-auf-Weisse-Haie/story/16123282). 
cognition can be discussed relative to the derivational as well as the sequential perspectives introduced above.

Extensively discussing the case of Phineas Gage-a railway worker who suffered a massive lesion in his prefrontal cortex, i.e. a brain centre that is very important for linking emotions and concepts-and relating this case to further neurocognitive evidence, Damasio (1994) presents very strong neurobiological arguments for the impact of emotions on cognitive processes of decision making. The empirical evidence shows that whenever we reason about a specific situation, prior emotional experiences with comparable situations strongly influence how we appraise the situation at hand (Damasio 2003 , p. 149). With regard to our example (1), the husband's hesitation may thus be explained on the basis of his uneasy feelings about the situation. He cannot reason about the tricky constellation without emoting about it.

Damasio (1999) presents these insights in a complex sequential model of emotional processing that implies an evolutionary perspective on how consciously perceptible emotional states have developed from evolutionarily more basic, uncontrollable and subconscious emotional reactions. In a discussion of the pragmatics of communicative choice making, Beeman (2014) reveals that such automatic emotional processes have an impact on the stylistic 'decisions' taken by a speaker. In a highly abbreviated form, Damasio's neuropsychological process model suggests that perceived stimuli directly activate emotion-triggering sites such as the amygdala, which themselves activate emotion-execution sites that cause uncontrollable bodily changes: facial expressions, increased heart rate, skin reaction, body posture, emotion-specific behaviours (see James 1884). Human beings are able to perceive and conceptualise such physiological and physical changes in our own bodies (Damasio 2003, p. 30). Thus, when we feel uneasy about something, we are able to perceive a change in our bodily state in combination with the thoughts that are momentarily associated with this state.

Through personal experience, certain concepts may become automatically linked with emotional reactions, which makes it possible to activate positive or negative feelings by thinking about a certain constellation without directly experiencing it. For instance, we can think about our colleagues and feel happy when doing so because we have had many happy encounters with them. Of course, such feelings may change, when more negative experiences modify the associative patterns between the concepts of our colleagues and the less pleasant bodily states experiences when they treated us badly.

Damasio's neurocognitive theory is compatible with the cognitive psychological theories of appraisal (Frijda 1986; Lazarus 1991; Scherer et al. 2001). They purport that emotions are triggered by cognitive processes of interpreting, i.e. appraising a given situation. Unlike Damasio's process model, which is grounded in the basic physiology of emotional reactions, appraisal theorists thus put their central emphasis on the different cognitive dimensions underlying the evocation of emotional/feeling states. Such appraisal processes are determined by our relationship to a specific situation, the goals we have in a specific situation as well as how relevant the situation is to our lives (Lazarus 1991). With regard to example (2) in our introduction, we will probably react rather soberly to a 
negative comment in an online newspaper commentary forum if we are occasional users of this service, if it is not our central goal to convince others of the correctness of our opinion and if the discussed issue is not very important to us. However, strong negative emotions such as contempt or anger would be triggered if we are frequent commentators and pursue the mission of convincing other readers because the argument at hand is highly relevant to our worldview. Accordingly, appraisal theory would predict that higher degrees of personal involvement, goal satisfaction or goal interruption as well as the personal relevance of a situation would trigger stronger emotions and feelings than lower ones.

Beyond having an intimate connection with emotional processing, cognition is also important for memorising and activating pre-established knowledge about appropriate context-specific behaviours, including situationally appropriate emotional behaviours (Andersen and Guerrero 1998, pp. 64-65; Locher and Langlotz 2008). Such knowledge is acquired through socialization (see Cook and Burdelski (Chap. 18), this volume). According to Hochschild $(1979,1983)$ two types of socially appropriate emotional behaviour must be distinguished. On the one hand, we must learn feeling rules, i.e. we must learn how to feel in a specific situation. For example, medical doctors must learn to express empathy with their patients without, however, feeling the same as them all the time (see also Locher and Koenig 2014; Locher 2017). Flight attendants must learn to project being in charge and positive even in highly stressful periods. Such feeling rules are closely related to display rules (Ekman and Friesen 1975). According to Andersen and Guerrero (1998, p. 54): 'these products of emotional socialization involve a learned response that modifies spontaneous emotional displays to be socially appropriate'. Thus, flight attendants must put on a smile even if they feel exhausted, whereas doctors should signal empathy about their patients' fate even if they cannot and should not feel sad about all their patients' misfortunes. The knowledge about feeling rules and display rules is stored in the form of corresponding cognitive schemata that are activated for judging and appraising the appropriateness of a given social situation. Thus, with regard to example (3) in the introduction, we know that a service transaction in a tourist office is linked to a certain (often highly culture-specific) transactional style. This style also involves expectations about appropriate emotional displays. In Switzerland, for instance, one would expect a certain degree of friendliness as signalled through a positively intonated voice and an occasional smile (see Langlotz 2015). But extreme displays of happiness as well as signals of annoyance or disinterest would violate the transactional norms for emotional displays. Such behaviours, which deviate from established feeling and display rules, would violate the expectations represented in culture-specific frames and activity types and most likely lead to negative appraisals. In other words, feeling rules and display rules provide emotion-specific benchmarks for appraisal processes.

For (im)politeness research the interface between emotion and cognition should therefore be of central interest with regard to the following perspectives. First, researchers should be interested in finding out how 
communicative situations and communicative acts lead to positive or negative appraisals and how such appraisals lead to emotion-driven (communicative) reactions. Research stressing this central role of appraisals in reactions to (im)politeness has been conducted by Culpeper and his colleagues (Culpeper 2011; Culpeper et al. 2014). Second, scholars working in interpersonal pragmatics should investigate the norms of emotionality (feeling rules) and emotional display (display rules) that specific speech communities associate with particular activity types. Breaching such expectations will again lead to negative appraisals and, in many cases, to negative emotional reactions including (im)politeness and conflict.

\title{
4.2 Emotions and sociality
}

Emotions are both personal and social phenomena. From the perspective of communication studies, Planalp (1999) claims:

\begin{abstract}
The mere fact that we communicate emotion implies that emotion itself is both personal and social. If our feelings were entirely personal, with no shared meaning and no implications for others, there would be no need to communicate them. Emotions might help us as individuals to orient to important concerns and guide our actions, but they would not interest anybody else. At the opposite extreme, there would also be no need to communicate emotions if they were entirely social. If members of a community felt in unison, emotions would serve to orient the group to common concerns and to coordinate behavior, but there would be no individual variation from one member to another. But emotions are neither purely personal nor purely social; they are both. Through communication, our personal emotional experiences are made available to others in society, and at the same time, social expectations about emotion are made known to us as individuals. Communication is a way of bridging the gap between the personal and the social sides of emotion. (Planalp 1999, p. 135, emphasis in original)
\end{abstract}

What we take from this quotation is that emotions have a fundamentally personal as well as social side-an observation which we can easily link to the current debate around the concept of face and identity construction. Both face and identity are bound to personal evaluations but are also shaped by communicative processes and thus turn into social phenomena (see also, Garcés-Conejos Blitvich 2013, p. 17; this volume). Emotions are intricately linked to sociality along three derivational levels: (i) phylogenetic, (ii) ontogenetic and (iii) social interactional. Many of the theories that deal with the construction of sociality along these levels are fundamentally important for

(Im)politeness. They show that emotion management is a crucial element for the symbolic construction of relationships.

From a phylogenetic perspective of human evolution emotions cannot be merely regarded as internal control mechanisms that manage the interaction of an organism with its environment. As Andersen and Guerrero (1998, p. 50) put it, emotions evolved 'as relatively universal communication systems that promoted the group survival of humans'. A very similar argument is also put forward in Turner's evolutionary theory of human sociality as grounded in emotionality (Turner 2000): 
Every facet of human endeavor is emotional. Without emotions, humans could not choose among behavioral alternatives, see themselves as objects, engage in face-to-face interpersonal behavior, organize groups, and construct large scale institutional systems cutting across entire societies and, today, a global network of societies. As much as language and the complex cultural systems that are made possible by language, humans' emotional capacities are what make patterns of human organization viable. (Turner 2000, p. 119)

Turner's theory puts forward that our biological ancestors were rather poorly equipped when they were forced to leave the arboreal habitats (due to retreat of tropical forests) and when they had to become adapted to the more open space of the African savanna. This pressure caused in hominoids the 'reorganization and elaboration of subcortical limbic structures, and their rewiring to neocortical and brain-stem systems, so as to produce an animal that could use and read a wide variety of emotional cues for enhanced social bonding' (Turner 2000, p. 20). Simply put, hominoids managed to survive because the development of highly differentiated emotional communicative skills allowed them to live in social groups that were strong and organised enough to face the odds of the savanna (see also, Baumeister and Leary 1995, p. 497). Emotional communication allowed them to produce positive and negative sanctions that helped them manage interpersonal relationships before language existed (Turner 2000, pp. 47-52). Such emotionally loaded social sanctions thus allowed hominoids to influence their communicative partners' orientation towards the social environment.

Moreover, the emotional repertoire had to be linked to moral codes (Turner 2000, pp. 52-6). Moral codes are expectations of appropriate behaviours including prescriptions and proscriptions. As cultural constructs, they have the power of compensating the absence of genetically endowed bioprograms for social behaviour. Moral coding makes the sociocultural management of emotions possible and corresponding interaction rituals (frames, including

feeling and display rules) are the communicative solution for implementing moral codes in socially appropriate behaviours. In this sense, interaction rituals are the cultural substitute for instinctive social behaviours.

This phylogenetic perspective is also reflected in the ontogenetic development of children and their bonding to their caretakers. As the research by Trevarthen and his colleagues has shown (Bråten 2007; Bråten and Trevarthen 2007; Trevarthen 1999, 2002; Powers and Trevarthen 2009), newborns are highly sensitive to emotional signals (facial expressions, pitch and force of voice) and pre-linguistic babies are able to establish basic communicative bonds to and empathy with their parents through emotional cueing from the age of two months onwards:

[M] icro-analyses of proto-conversations with two-month-olds have revealed that infants are endowed with a cerebral system that enables direct perception of interests and feelings in an other person and responsive attunement permitting delicate, emotionally regulated engagements. (Bråten and Trevarthen 2007, p. 21) 
Emotional communication can thus be taken as an ontologically basic form of intersubjective engagement (Foolen et al. 2012). Emotional communication is highly important for the generation of empathy, which can be considered the emotional 'glue' of sociality (DeWaal 2007). This insight is also supported by modern neurobiological research (Bauer 2005). The importance of emotional cues in interpersonal interaction is also evidenced by Tronick's (2005) still face experiment, which shows how the absence of emotional signaling destroys the social bonds between babies and their mothers and causes great distress in them. Therefore, the socioemotional roots constitute the foundation for further dialogic and interactional competence including the complex management of relationships through language. Humans have a 'need for frequent, affectively pleasant interactions with a few other people in the context of a temporally stable and enduring framework of affective concern for each other's welfare' (Baumeister and Leary 1995, p. 497). Following Plutchik's derivational perspective on emotions, we therefore claim that the emotional component in human social interaction and communication remains quintessential for the management of interpersonal relationships throughout an individual's life (see Arndt and Janney 1985, p. 282). This leads us to the social interactional links between emotions and human sociality.

The link between emotions and human sociality is highly reciprocal. On the one hand, as the phylogenetic and ontogenetic perspectives suggest, emotions are the glue for social bonding and give the edge to acts of social sanctioning (see Boxer and Cortés-Conde 1997). On the other hand, interpersonal relationships also constitute the most important source for emotions. Andersen and Guerrero (1998, p. 64) argue that 'the primary

Table 12.3. Emotions and their social-interactional elicitors (summarised from Andersen and Guerrero 1998).

\begin{tabular}{ll}
\hline Emotion: & Social elicitor: \\
\hline Happiness/joy & $\begin{array}{l}\text { Sharing happy and euphoric states with others } \\
\text { (non-social antecedents are rare) }\end{array}$ \\
\hline Love/affection & $\begin{array}{l}\text { Shared times and experiences with partner } \\
\text { (unrequited love causes distress) }\end{array}$ \\
\hline Pride & Positive self-evaluation based on other's approval \\
\hline Anger & Other's interference with one's personal goals is the most \\
& $\begin{array}{l}\text { frequent source of anger } \\
\text { Communicative moves of others: insults, criticism, rejection }\end{array}$ \\
\hline Fear/anxiety & Instigation through threats \\
& Fear of presenting oneself to others/interacting with others \\
\hline Sadness & Sadness is mainly caused by social interaction. \\
Grief & Grief is caused by loss of relationship. \\
Depression & Depression is associated with social isolation. \\
\hline Jealousy & Central social emotion: caused by real, anticipated, or \\
& imagined interaction of close friend or partner with third party \\
\hline $\begin{array}{l}\text { Guilt } \\
\text { Shame }\end{array}$ & Self-conscious emotions \\
Embarrassment & Result from social interaction, i.e. transgressions of norms and \\
their appraisal by oneself and the interactional partners
\end{tabular}

Elicitor of emotions is interpersonal interaction. [...]. Moreover, people often strategically induce emotional states in others as a way of achieving interpersonal goals.' In their meta- 
analysis, they discuss how a number of emotions are triggered and elicited through social interaction (Table 12.3).

As Table 12.3 shows, communication as a source of emotion thus involves a number of aspects that are of direct relevance for relational work and (im)politeness and provide a sharper picture of how emotional reactions and feeling states are tied to social interaction and corresponding norms. With a view to the social elicitors, the process model of emotion can be given a social interactional reinterpretation (Table 12.4).

This social reinterpretation of the sequential model of emotions leads us to the problem of how emotions are communicated through emotional cues.

The perspective presented in this section thus ties in with the connection between emotion and cognition discussed above. When analysing acts of (im)politeness, researchers should pay close attention to the social-interactional causes of (im)polite behaviours and how these causes affect the interactants' emotional orientation to the current speech activity, their communicative partners and the negotiation and understanding of roles. ${ }^{6}$ It is this link

Table 12.4. Sequential model of the social side of emotional processes.

\begin{tabular}{|c|c|c|c|c|}
\hline 1 & 2 & 3 & 4 & 5 \\
\hline $\begin{array}{l}\text { Stimuli: } \\
\text { social- } \\
\text { interactional } \\
\text { causes }\end{array}$ & $\begin{array}{l}\text { Social- } \\
\text { normative } \\
\text { appraisals } \\
\text { relative to } \\
\text { personal goals } \\
\text { and moral } \\
\text { codes }\end{array}$ & $\begin{array}{l}\text { Socially } \\
\text { determined } \\
\text { physiological } \\
\text { changes and } \\
\text { feeling } \\
\text { states }\end{array}$ & $\begin{array}{l}\text { Socially } \\
\text { expected action } \\
\text { tendencies, } \\
\text { actions, and } \\
\text { expressions for } \\
\text { specific roles } \\
\text { within social } \\
\text { practices }\end{array}$ & $\begin{array}{l}\text { Social-normative } \\
\text { regulatives = } \\
\text { Display rules }\end{array}$ \\
\hline $\begin{array}{l}\text { Customer is } \\
\text { confronted } \\
\text { with a harsh } \\
\text { service } \\
\text { provider. }\end{array}$ & $\begin{array}{l}\text { As customer } \\
\text { wishes to be } \\
\text { treated in a } \\
\text { friendly } \\
\text { manner, this } \\
\text { conduct is } \\
\text { considered } \\
\text { inappropriate. }\end{array}$ & $\begin{array}{l}\text { Customer } \\
\text { feels } \\
\text { annoyance. }\end{array}$ & $\begin{array}{l}\text { The feeling rules } \\
\text { of the social } \\
\text { situation } \\
\text { demand a } \\
\text { 'balanced' form } \\
\text { of emotional } \\
\text { display. This is } \\
\text { in } \\
\text { conflict with the } \\
\text { customer's } \\
\text { current } \\
\text { emotional state. }\end{array}$ & $\begin{array}{l}\text { The customer } \\
\text { may } \\
\text { inhibit the } \\
\text { display of } \\
\text { his/her } \\
\text { anger or let the } \\
\text { emotion out, } \\
\text { thereby socially } \\
\text { sanctioning the } \\
\text { service } \\
\text { provider's } \\
\text { unfriendly } \\
\text { behaviour. }\end{array}$ \\
\hline
\end{tabular}

between sociality and emotions that allows us to reiterate the importance of research that is concerned with the link between face, emotions and identity construction within interpersonal pragmatics (Garcés-Conejos Blitvich 2013; Locher 2008; Ruhi 2007, 2009; Spencer-Oatey 2007, 2011), as exemplified in the block quotation by Garcés-Conejos Blitvich (2013, p. 17) in Sect. 3.

\footnotetext{
${ }^{6}$ Arndt and Janney $(1985$, p. 294) have proposed a valuable model for the 'cross-modal modulation of positive and negative feelings'. Their framework outlines how emotion-related parameters, such as confidence, positive and negative affect, and involvement, are cued in interpersonal communication.
} 


\subsection{Communicative observables of emotions}

As the juxtaposition of the hidden, personal side of emotion, with the social side of emotion suggests, the communicative sharing of emotional states is centrally determined through complex patterns of emotional signalling. We can distinguish two communicative perspectives through which emotions become observable for linguistic analysis: (i) emotional cues as they are produced in interpersonal interaction and (ii) meta-comments on and descriptions of internal emotional states.

With regard to (i), interactants combine emotional cues from different communicative modalities (verbal, vocal, facial, bodily) in dynamic conversational exchanges (see Arndt and Janney 1985; Planalp 1998; Döveling et al. 2010; Micheli 2008, pp. 5-6; Tables 12.5 and 12.6).

From the perspective of interpersonal pragmatics, it is of central interest how participants signal their emotional stances to their interlocutors, and how these signals are taken up by the recipient in order to analyse the

Table 12.5. Planalp's (1998) overview of emotional cues (see Langlotz and Locher 2013, p. 94).

\begin{tabular}{ll}
\hline Class of cues: & Forms of realisation: \\
\hline vocal cues & $\begin{array}{l}\text { voice quality: low, loud, slow, fast, trembling, high-pitched, } \\
\text { monotonous, animate voice }\end{array}$ \\
\hline verbal cues & $\begin{array}{l}\text { language-specific emotion vocabularies } \\
\text { metaphors } \\
\text { speech acts } \\
\text { emotional discourse practices, e.g. therapeutic discourse }\end{array}$ \\
\hline body cues & $\begin{array}{l}\text { animated, energetic movement } \\
\text { physical actions: throwing things, making threatening } \\
\text { movements, kissing, caressing }\end{array}$ \\
& $\begin{array}{l}\text { gait: walking heavily, lightly, arm swing, length/speed of stride } \\
\text { body posture: stiff/rigid, droopy, upright } \\
\text { hands/arms gestures: hand emblems, clenching hands or fists }\end{array}$ \\
\hline physiological cues & Blushing, pupil dilation, heart rate, breathing, skin \\
& $\begin{array}{l}\text { temperature } \\
\text { facial cues }\end{array}$ \\
\hline
\end{tabular}


Table 12.6. Ochs and Schieffelin's (1989) classificatory grid, abbreviated for the Linguistic expression of affect relevant to our data set (see also, Langlotz and Locher 2013, p. 97).

\begin{tabular}{ll}
\hline Level of analysis: & Type of cue: \\
\hline vocal features & loudness \\
\hline voice quality & lengthening \\
& stress \\
\hline morphosyntax & pronouns: the use of third person pronouns to refer to the \\
& addressee \\
\hline lexicon & interjections \\
& descriptive terms for humans \\
\hline discourse structure & affective speech acts: \\
& laments \\
& threats \\
& exclamations \\
\hline
\end{tabular}

complex and multimodal semiotic construction of relational meaning. From an interactional perspective the analytical focus thus lies on the external emotional 'representations' in communicative moves (see Pfänder and Gülich 2013), rather than on the 'internal' psychological or neuropsychological research perspective on how people emote and feel (e.g. Bänziger and Scherer 2010). These insights suggest that in the analysis of any communicative act of relational work, the set of emotional signals that accompany such messages should be considered. This invites multimodal analyses of 'speech acts' (see, e.g. Goodwin et al. 2002; Matoesian 2005) rather than traditional linguistic analyses of the verbal structure of communicative acts alone. Research on emotional displays in psychology used to focus on facial expressions. Most prominently, Ekman and his colleagues argued for a universal set of six basic emotions that are automatically displayed in highly similar ways and recognized with a considerable degree of accuracy across cultures (Ekman 1992, 2003; Ekman and Friesen 1975, 1978). This limitation of emotional expression to the face and a presupposed set of basic emotions has been criticized and contested in communication studies (e.g. Planalp 1998, 1999) and linguistic anthropology (e.g. Couper-Kuhlen 2011; Enfield and Wierzbicka 2002; Pavlenko 2002; Wilce 2009). This literature has demonstrated the multimodality, performativity and cultural relativity of emotion concepts and corresponding emotional expressions. In addition, coding schemes for facial (Ekman and Friesen 1978), vocal (Goodwin et al. 2002; Reber 2012), verbal (Fiehler 2002; Ochs and Schieffelin 1989; Schwarz-Friesel 2007) and bodily cues (Streeck 2009) exist. But these coding schemes primarily concentrate on one communicative modality. Hence, Planalp's assessment from 1998 regarding the lack of integration of these findings into a coherent model is still valid:

Even though researchers tend to study amputated heads, decapitated bodies, disembodied and content-free voices, and decontextualized words, we know that in some way they go together. What is singularly lacking is any plausible account of how cues are combined into complex multichannel messages about emotion, much less accounts of how they are produced and interpreted. (Planalp 1998, p. 37) 
In more recent linguistic work, interesting frameworks have been proposed to chart the multimodal dimensions of emotional signalling (e.g. Fiehler 2002; Wilce 2009). But only very few studies-mostly from the fields of conversation analysis, praxeology and anthropological linguistics - have actually investigated the dynamics of this multimodality in actual embodied practices of relational work (Goodwin and Goodwin 2001; Goodwin et al. 2002; Matoesian 2005; Pepin 2008). In line with these multimodal interactional perspectives, Langlotz and Locher (2013) have proposed a framework for analysing emotional signalling in relational work. Their model is rooted in Clark's (1996) theory of language use. He proposes that interactors do not merely encode meanings into symbolic units but rather engage in complex processes of multimodal signalling for describing, indexing and demonstrating their stances to one another. Moreover, Clark highlights that the creation of meaning is achieved by joint actions in which the speaker and the listener simultaneously play active roles. Joint processes of emotional signalling serve the semiotic construction and management of relational meaning between the interactional partners. The interactional partners employ multimodal emotional displays to perform complex communicative acts of social sanctioning and moral coding.

From an interactional perspective it is therefore necessary to focus on the interactional design as well as the recipient take-up of communicative moves with a socioemotional impact. Both the signalled emotional values and their reception are claimed to be essential for discursively modulating interpersonal relationships. When analysing interactions, researchers are faced with a dynamic activation of the repertoire of emotional cues. While conspicuous emotional displays may be absent, interactors can also become entangled in emotional 'interaction chains', i.e. emotions which trigger further emotions. Furthermore, interactants may make rhetorical/strategic use of emotional cues.

Emotional cues play a central role in the immediate communication of emotion and interpersonal supportiveness, as highlighted by Arndt and Janney (1985). Thus, they belong to the social side of emotionality. However, as outlined below, emotions also have a personal side. Through such cues a recipient can make judgements or hypotheses about this personal side. However, in many cases to move beyond the level of emotional stance and to know what another person really feels, we depend on his or her explicit description or meta-comments. Along these lines, Culpeper et al. (2014) have proposed an analytical framework to compare intercultural differences in the emotional reactions to impolite communicative situations. Locher and Koenig (2014) and Locher (2017) have also analysed emotional meta-comments by medical students reflecting on how they experienced their relationships to and interactions with patients (e.g. some students reported on their fear of coming across as impolite and rude). Meta-comments thus allow us to gain post hoc access to the feeling states experienced by interactors in relational episodes. 


\section{Sketching paths for empirical analysis}

With regard to the dimensions outlined above, researchers of (im)politeness can refer to the following toolbox of analytical concepts presented in Table 12.7 when analysing the link between (im)politeness and emotion in actual interaction.

While we lack the space to present detailed empirical work, we will briefly sketch the analysis of a Monty Python's Flying Circus (series 2, episode 5, 1970) clip of a shop interaction building on what we presented in Table 12.4 as a sequential model for the social side of emotional processes (Transcript 1). 


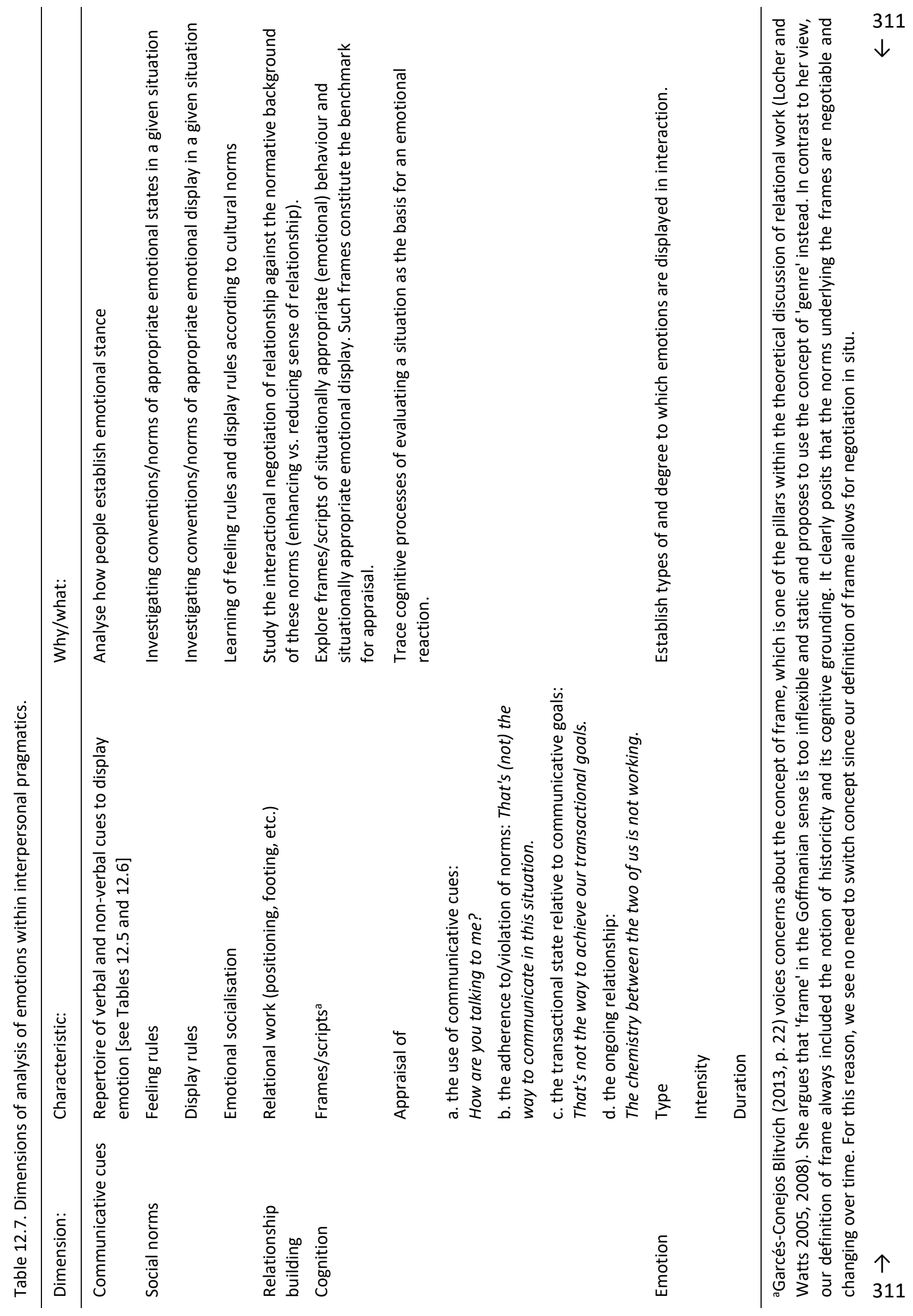


The humorous scene shows a shop assistant and a customer interacting with each other

in a butcher's shop; however, the interaction does not follow the to-be-expected script.

Transcript (1): Monty Python's Flying Circus: Live from the Grill-O-Mat, The Man Who is Alternately Rude and Polite (series 2, episode 5, 1970).

Setting: Butcher's shop; shop assistant (SA) behind counter; customer (C) in front of the counter.

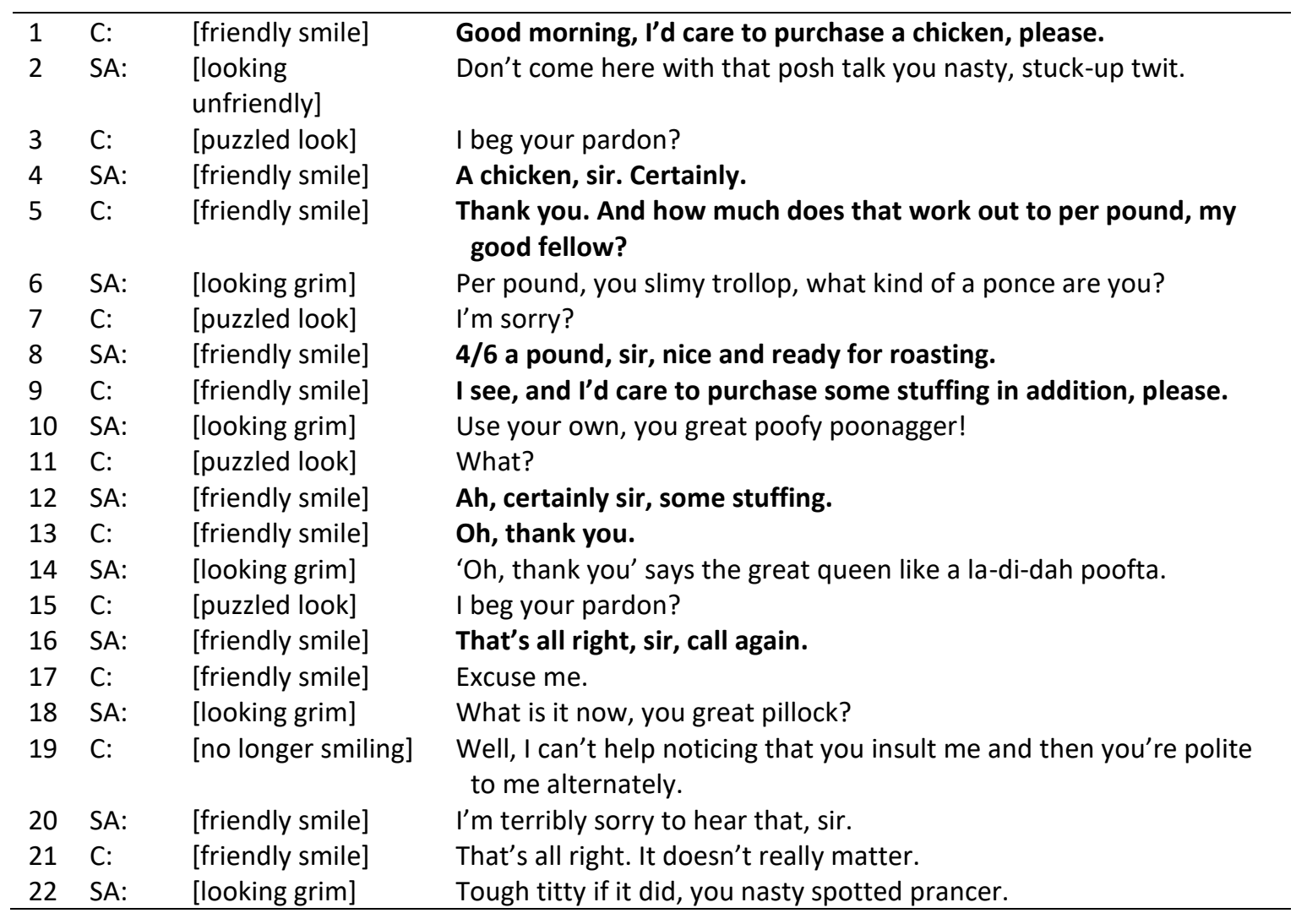

In transcript 1 the text in bold shows the expected interaction for shop encounters in England, which is carried out with a positive emotional orientation to each other indicated by the accompanying friendly smiles and the careful and respectful choice of vocabulary. Intervening between the turns, we find breaches of the expected conduct by the shop assistant (this incongruity constituting the source of the humour; Attardo 1994). In contrast to the expected response, the shop assistant breaks the frame of the shop interaction by insulting the customer. The visibly puzzled customer reacts by stating 'I beg your pardon?' and immediately receives a perfectly adequate response to the original request. The reassured customer returns to the activity frame of the shop interaction by voicing the next request, only to be at the receiving end of more insults. This pattern is repeated several times. In line 17, the customer moves the interaction to a discussion of appropriateness and uses meta-pragmatic comments to express his puzzlement about the alternation of insults with polite behaviour. In what follows, we will make selective comments on the analytical dimensions in Table 12.7 with reference to salient instances in this sketch. We intend to illustrate the potential for interpersonal pragmatic research rather than providing a detailed analysis. 
A number of emotions seem to play a role in the transaction. The shop assistant expresses contempt for the customer and directs his anger against his interactional partner (2). These negative emotions are immediately followed by the seller's shift to a state of happy support (4). The customer also starts by addressing the shop assistant in a positive and happy mood $(1,5,9,13)$, but in reaction to the butcher's take-up of his requests, his emotional state shifts to puzzlement $(3,7,11,15)$ and increasing irritation (17). We can perceive the interactors' emotional stances through the communicative observables performed by them.

With regard to the repertoire of multimodal cues to communicate emotional stance, vocal, facial, verbal and body cues seem particularly salient in the sketch. Whenever the shop assistant switches from taking a positive and polite stance to taking an aggressive and impolite one, this is marked by a change of intonation. While negative stance is expressed through more stress and vocal force (e.g. 2), positive stance is mediated through the higher pitched voice and rising intonation (e.g. 4). This is usually accompanied by a smiling versus grim facial expression, which could be more precisely described by applying Ekman and Friesen's facial action coding system (Ekman and Friesen 1975, 1978, see also Ekman 2003). The emotional force of the seller's lexical choices is immediately evident. He uses highly offensive, derogatory and negatively connoted membership categorisation devices (Sacks 1992). The customer's reactions primarily show tokens of puzzlement along the same dimensions of cues. Interestingly, the customer's orientation away from and towards the shop assistant can also be seen in the former's upward and downward head movements (14-17), which support both avoidance and establishment of eye contact. His puzzlement becomes best apparent in the meta-communicative comment he makes in (19).

Concerning the links between these emotional displays and corresponding social rules, every adult having been socialised in a British context will immediately recognise that the shop assistant breaks the norms of appropriate social conduct in a seller-buyer interaction. Of course, this break of convention constitutes the backbone of humour in the sketch as the shop assistant breaches both feeling rules and display rules. The conventional feeling rule

for a seller is: be friendly to your customer and make him/her feel at ease. Obviously, this is not the seller's intention here: He vents his annoyance with the stilted customer in a very unrestrained way. In doing so, he also violates emotional display rules. Even if a service provider were annoyed with customers or irritated by their behaviour, by convention he/she would not be given free lease to express anger and contempt by activating the arsenal of negative emotional cues outlined above. Thus, the butcher not only breaks the conventional feeling rule of being friendly but also violates the display rule: if you don't like your customer, don't show your negative attitude. These feeling rules and display rules are part of the knowledge we associate with the seller-buyer frame. Their violation triggers appraisal processes and emotional reactions. The audience may also vicariously experience the hidden pleasure of breaking such rules. 
The client's meta-comment in (19) directly addresses the shop assistant's communicative oscillation between two frames: (a) seller-buyer talk and (b) abuse. Throughout the interaction the frames are cued through typical features such as the boldtype moves in the transcript, which are conventional for (a). The rapid and unmediated switch to (b) comes with a conspicuous change of speech style. Both for the audience of the sketch as well as for the protagonists within the fictional setting, these frames constitute benchmarks for appraisal processes. On the one hand, as spectators we may laugh at the shop assistant's inappropriate and norm-deviating use of cues and the 'schizophrenic' situation that is evoked through them. The customers' appraisal, on the other hand, is rather characterised by surprise and increasing irritation as he is repeatedly faced with the unexpected frame of abuse.

The relational work conducted by the interactional partners in the sketch here is also funny because it plays with the sequentiality of social positioning. Whenever the customer attempts to adapt his emotional stance to the shop assistant's highly unconventional impoliteness, the latter changes back to the normal frame and thus puts the customer into the sequential offside. While the customer believes that everything is back to normal again, he is always one 'step' behind throughout the interaction and he does not manage to adapt his emotional stance to the outrageous impoliteness. As a result, he stays trapped in a state of puzzlement and his reactions do not really succeed in sanctioning the latter's inappropriate behaviour. This 'pattern' is even maintained after the customer has asked for clarification of the seller's stance-taking by his meta-comment in (19). Thus, while the interaction in the sketch appears to be highly emotional in an unconventional way, the emotional displays do not seem to have a direct impact on the way the relationship between the interactors is negotiated. Instead of establishing a negative emotional contagion

chain of abuse and counter-abuse, as would be typical of intense conflict talk (Dersley and Wootton 2001), the sketch stages a scene of communicative oscillation. This adds further abnormality and incongruity to the sketch.

\section{Conclusions and outlook}

In this overview of the importance of emotions for the study of (im)politeness and interpersonal pragmatics more generally, we have aimed to give background knowledge to those not familiar with research on emotions and, on the basis of a short literature review, to point out research interfaces that warrant further research. Let us recapitulate some of our observations.

We are not saying that emotions are the same as relations and we are not suggesting we should replace the concept of 'relational work' with 'emotional work'. Instead, we want to highlight that emotions play a fundamental role in the creation of any type of pragmatic meaning, no matter whether there is recognition of intentions or awareness of intentions (by $\mathrm{S}$ or $\mathrm{H}) .^{7}$ We wish to point out the fundamental emotional component in cognitive

\footnotetext{
${ }^{7}$ In other words, we are not, as Kádár and Haugh (2013, p. 225) claim, arguing that emotions only go together
} 
appraisals which are at the heart of judgments about appropriate or inappropriate behaviour (see Locher and Langlotz 2008; Sect. 4.1 on emotions and cognition). Emotions thus play an important part in arriving at emic judgements on relational work so that they have a clear place in the theoretical arguments of interpersonal pragmatics.

In line with others (Ruhi 2007, 2009; Garcés-Conejos Blitvich 2013; Locher 2008; Spencer-Oatey 2007, 2011), we claim that emotions are intricately tied to the concepts of face and identity construction. While our self-concepts are linked to personal emotions that we do not always wish to share with our communicative partners, what we think and feel about ourselves is to a very large extent shaped through interaction and the emotional stances that our interlocutors express towards us. This is because emotions are directly linked to sociality and relationship building. In addition, our understanding of who we are and what lines of identity we want to project are fundamentally linked to the understanding of rights and obligations of particular situated roles. Being successful or unsuccessful in creating identities has emotional consequences that will impact ensuing interaction.

From a phenomenological point of view, we addressed communicative observables of emotions. Here we offered a set of lists that might help scholars to identify multimodal emotional cues. Emotional stance can thus be signalled

in a combination of different modes. However, we are not arguing that analysts can or should only work with those cues that can be easily identified in the surface structure of communication. Our previous comments about the fundamental nature of emotions for cognition and sociality also pave the way for in-depth (critical) discourse analysis that engages with the underlying ideologies involving emotions that are behind feeling and emotion display rules. As we point out elsewhere (Langlotz and Locher 2013, p. 104), ' $[w]$ hen scrutinizing naturally-occurring data one also has to be acutely aware of the fact that emotional display rules may supress explicit emotional signalling in a given interaction'. As a matter of fact, we find data that presents unmarked, smooth interaction as interesting as behaviour that is clearly marked as negative or positive. Having said this, it is probably safe to say that we can usually only observe the tip of the iceberg of the complex and full emotional world of interactants and their potentially different interpretations of events and the related emotional components. Nevertheless, 'those emotional orientations that are signalled as well as the striking absence of expected emotional displays must be considered to play an important role for the study of relational work as a discursive phenomenon' (Langlotz and Locher 2013, p. 105).

In theory, scholars of (im)politeness could be satisfied with acknowledging the fundamental importance of emotions for interpersonal pragmatics and leave it at that. This seems to have been the path that many of the early politeness theories have taken (with the exception of Arndt and Janney 1985). However, we believe that more research efforts in this field are warranted since emotions are such a fundamental part of appraisals and of relating and thus also of assessing relational work. Even when we analysts cannot always access explicit surface structures or clearly assignable emotional stance, emotions

with recognition of intentions or with awareness of intentions (by $\mathrm{S}$ or $\mathrm{H}$ ). 
are underlying any human interaction. It is worthwhile studying this quite simply because our concepts of ourselves are at stake and we are quite clearly emotionally involved with these projections/understandings. We thus suggest that the (im)politeness field can benefit from further exploring the link between emotions, identity construction and sociality.

\section{References}

Andersen, P.A., and L.K. Guerrero. 1998. Principles of Communication and Emotion in Social Interaction. In Handbook of Communication and Emotion: Research, Theory, Applications, and Contexts, ed. P.A. Andersen and L.K. Guerrero, 49-96. San Diego: Academic Press.

Arndt, H., and R.W. Janney. 1985. Politeness Revisited: Cross-Modal Supportive Strategies. International Review of Applied Linguistics in Language Teaching 23 (1-4): 281-300. doi:10.1515/iral.1985.23.1-4.281.

Attardo, S. 1994. Linguistic Theories of Humor. Berlin: Mouton de Gruyter.

Bänziger, T., and K.R. Scherer. 2010. Introducing the Geneva Multimodal Emotion Portrayal (GEMEP) Corpus. In Blueprint for Affective Computing: A Sourcebook, ed. K.R. Scherer, T. Bänziger, and E.B. Roesch, 271-294. Oxford, UK: Oxford University Press.

Barrett, L.F. 1998. The Future of Emotion Research. The Affect Scientist 12 (2): 6-8.

Bauer, J. 2005. Warum ich fühle was du fühlst - Intuitive Kommunikation und das Geheimnis der Spiegelneurone. Hamburg: Hoffmann und Campe.

Baumeister, R.F., and M. Leary. 1995. The Need to Belong: Desire for Interpersonal Attachments as a Fundamental Human Motivation. Psychological Bulletin 177: 497-529.

Bednarek, M. 2008. Emotion Talk Across Corpora. Houndmills: Palgrave MacMillan.

Beeman, W.O. 2014. Emotion and Instantaneous Choice in Interactional Linguistic Pragmatics: Cross-Cultural Perspectives. Journal of Pragmatics 69: 52-62. doi:10.1016/j.pragma.2014.04.007.

Boxer, D., and F. Cortés-Conde. 1997. From Bonding to Biting: Conversational Joking and Identity Display. Journal of Pragmatics 27 (3): 275-295. doi:10.1016/S0378-2166(96)00031-8.

Bråten, S. 2007. Introducing the Matrix and Multiple Layers of Intersubjectivity and Empathy. In On Being Moved: From Mirror Neurons to Empathy, ed. S. Bråten, 1-17. Amsterdam: John Benjamins.

Bråten, S., and C. Trewarthen. 2007. Prologue: From Infant Intersubjectivity and Participant Movements to Simulation and Conversation in Cultural Common Sense. In On Being Moved: From Mirror Neurons to Empathy, ed. S. Bråten, 21-34. Amsterdam: John Benjamins.

Brown, P., and S.C. Levinson. 1987. Politeness. Some Universals in Language Usage. Cambridge, UK: Cambridge University Press.

Burke, P.J., and J.E. Stets. 2009. Identity Theory. Oxford, UK: Oxford University Press.

Chang, W.-L.M., and M. Haugh. 2011. Strategic Embarrassment and Face Threatening in Business Interactions. Journal of Pragmatics 43 (12): 2948-2963. doi:10.1016/j.pragma.2011.05.009. Clark, H.H. 1996. Using Language. Cambridge, UK: Cambridge University Press.

Couper-Kuhlen, E. 2011. Affectivity in Cross-Linguistic and Cross-Cultural Perspective. In Sprachen in mobilisierten Kulturen: Aspekte der Migrationslinguistik, ed. T. Stehl, 231-257. Potsdam: Universitätsverlag. 
Culpeper, J. 2010. Conventionalised Impoliteness Formulae. Journal of Pragmatics 42 (12): 3232 3245. doi:10.1016/j.pragma.2010.05.007.

-. 2011. Impoliteness. Using Language to Cause Offence. Cambridge, UK: Cambridge University Press.

Culpeper, J., and M. Haugh. 2014. Pragmatics and the English Language. Houndmills: Palgrave MacMillan.

Culpeper, J., G. Schauer, L. Marti, M. Mei, and M. Nevala. 2014. Impoliteness and Emotions in a

Cross-Cultural Perspective. In Emotion, Affect, Sentiment: The Language and Aesthetics of Feeling, ed. A. Soltysik Monnet and A. Langlotz, 67-88. Tübingen: Narr.

Damasio, A. 1994. Descartes' Error: Emotion, Reason, and the Human Brain. London: Penguin.

-. 1999. The Feeling of What Happens: Body and Emotion in the Making of Consciousness. San Diego: Harcourt.

-. 2003. Looking for Spinoza. Joy, Sorrow, and the Feeling Brain. Orlando: Harcourt.

-. 2004. Emotions and Feelings: A Neurobiological Perspective. In Feelings and Emotions - The Amsterdam Symposium, ed. A. Manstead, N. Frijda, and A. Fischer, 49-57. Cambridge, UK: Cambridge University Press.

Darwin, C.R. 1872. The Expression of the Emotions in Man and Animals. London: John Murray. De Waal, F.B.M. 2007. The 'Russian Doll' Model of Empathy and Imitation. In On Being Moved: From Mirror Neurons to Empathy, ed. S. Bråten, 49-69. Amsterdam: John Benjamins.

Dersley, I., and A.J. Wootton. 2001. In the Heat of the Sequence: Interactional Features Preceding Walkouts from Argumentative Talk. Language in Society 30 (4): 611-638.

Doveling, K., C. Von Scheve, and E.A. Konijn, eds. 2010. The Routledge Handbook of Emotions and Mass Media. London: Routledge.

Edwards, D. 1999. Emotion Discourse. Culture \& Psychology 5 (3): 271-291. doi:10.1177/1354067X9953001.

Ekman, P. 1992. An Argument for Basic Emotions. Cognition and Emotion 6 (3/4): 169-200. doi:10.1080/02699939208411068.

-. 2003. Emotions Revealed. Recognizing Faces, Feelings, and Their Triggers to Improve Communication and Emotional Life. New York: Times Book.

Ekman, P., and W.V. Friesen. 1969. The Repertoire of Nonverbal Behavior: Categories, Origins, Usage and Coding. Semiotica 1 (1): 49-98.

-. 1975. Unmasking the Face. A Guide to Recognizing Emotions from Facial Expressions. Englewood Cliffs: Prentice Hall.

-. 1978. Facial Action Coding System. A Technique for the Measurement of Facial Movement. Palo Alto: Consulting Psychologists Press.

Enfield, N., and A. Wierzbicka. 2002. Introduction: The Body in Description of Emotion. Pragmatics and Cognition 10 (1/2): 1-25. doi:10.1075/pc.10.12.02enf.

Fiehler, R. 2002. How to do Emotions with Words: Emotionality in Conversations. In The Verbal Communication of Emotions: Interdisciplinary Perspectives, ed. S.R. Fussell, 79-106. Mahwah: Lawrence Erlbaum.

Foolen, A. 2012. The Relevance of Emotion for Language and Linguistics. In Moving Ourselves, Moving Others: Motion and Emotion in Intersubjectivity, Consciousness and Language, ed. A. Foolen, U.M. Lüdtke, T.P. Racine, and J. Zlatev, 349-369. Amsterdam: John Benjamins. Benjamins. 
Frijda, N. 1986. The Emotions. Studies in Emotion and Social Interaction. Cambridge, UK: Cambridge University Press.

Garcés-Conejos Blitvich, P. 2013. Introduction: Face, Identity and (Im)Politenessliteness. Looking Backward, Moving Forward: From Goffman to Practice Theory. Journal of Politeness Research 9 (1): 1-33. doi:10.1515/pr-2013-0001.

Goffman, E. 1967. Interaction Ritual: Essays on Face-to-Face Behavior. Garden City: Anchor Books.

Goodwin, M.H., and C. Goodwin. 2001. Emotion Within Situated Activity. In Linguistic Anthropology: A Reader, ed. A. Duranti, 239-257. Malden: Blackwell.

Goodwin, M.H., C. Goodwin, and M. Yaeger-Dror. 2002. Multimodality in Girls' Game Disputes. Journal of Pragmatics 34 (10/11): 1621-1649. doi:10.1016/S0378-2166(02)00078-4.

Haidt, J. 2003. The Moral Emotion. In Handbook of Affective Sciences, ed. R.J. Davidson, K.R. Scherer, and H. Hill Goldsmith, 852-870. Oxford, UK: Oxford University Press.

Harré, R., ed. 1986. The Social Construction of the Emotions. Oxford, UK: Blackwell.

Haugh, M., D. Kádár, and S. Mills. 2013. Interpersonal Pragmatics: Issues and Debates. Journal of Pragmatics 58: 1-11. doi:10.1016/j.pragma.2013.09.009.

Hochschild, A.R. 1979. Emotion Work, Feeling Rules, and Social Structure. American Journal of Sociology 85 (3): 551-575.

-. 1983. The Managed Heart: Commercialization of Human Feeling. Berkeley: University of California Press.

James, W. 1884. What Is an Emotion? Mind 9 (34): 188-205.

Kádár, D., and M. Haugh. 2013. Understanding Politeness. Cambridge, UK: Cambridge University Press.

Kienpointner, M. 2008. Impoliteness and Emotional Arguments. Journal of Politeness Research 4 (2): 243-265. doi:10.1515/JPLR.2008.012.

Langlotz, A. 2010. Social Cognition. In Interpersonal Pragmatics, ed. M.A. Locher and S.L. Graham, 167-202. Berlin: Mouton de Gruyter.

-. 2015. Creating Social Orientation Through Language: A Socio-Cognitive Theory of Situated Social Meaning. Amsterdam: John Benjamins.

Langlotz, A., and M.A. Locher. 2012. Ways of Communicating Emotional Stance in Online Disagreements. Journal of Pragmatics 44 (12): 1591-1606. doi:10.1016/j.pragma.2012.04.002.

-. 2013. The Role of Emotions in Relational Work. Journal of Pragmatics 58: 87-107. doi:10.1016/j.pragma.2013.05.014.

Langlotz, A., and A. Soltysik Monnet, eds. 2014. Emotion, Affect, Sentiment: The Language and Aesthetics of Feeling. Tübingen: Narr.

Lazarus, R.S. 1991. Progress on a Cognitive-Motivational-Relational Theory of Emotion. American 320 Psychologist 46 (8): 819-834. doi:10.1037/0003-066X.46.8.819.

LeDoux, J. 1998. The Emotional Brain: The Mysterious Underpinnings of Emotional Life. New York: Touchstone.

Leech, G.N. 1983. Principles of Pragmatics. New York: Longman.

-. 2014. The Pragmatics of Politeness. Oxford, UK: Oxford University Press.

Locher, M.A. 2004. Power and Politeness in Action: Disagreements in Oral Communication. Berlin: Mouton de Gruyter. 
-. 2008. Relational Work, Politeness and Identity Construction. In Handbooks of Applied Linguistics. Volume 2: Interpersonal Communication, ed. G. Antos, E. Ventola, and T. Weber, 509-540. Berlin: Mouton de Gruyter.

Locher, M.A. 2017. Reflective Writing in Medical Practice. A Linguistic Perspective. Bristol: Multilingual Matters.

Locher, M.A., and R. Koenig. 2014. 'All I Could Do Was Hand Her Another Tissue' - Handling Emotions as a Challenge in Reflective Writing Texts by Medical Students. In Emotion, Affect, Sentiment: The Language and Aesthetics of Feeling, ed. A. Soltysik Monnet and A. Langlotz, 121-142. Tübingen: Narr.

Locher, M.A., and A. Langlotz. 2008. Relational Work: At the Intersection of Cognition, Interaction and Emotion. Bulletin Suisse de Linguistique Appliquée (VALS-ASLA) 88: 165-191. Retrieved from http://doc.rero.ch/record/11876/files/bulletin_vals_asla_2008_088.pdf.

Locher, M.A., and R.J. Watts. 2005. Politeness Theory and Relational Work. Journal of Politeness Research 1 (1): 9-33. doi:10.1515/jplr.2005.1.1.9.

-. 2008. Relational Work and Impoliteness: Negotiating Norms of Linguistic Behaviour. In Impoliteness in Language. Studies on Its Interplay with Power in Theory and Practice, ed. D. Bousfield and M.A. Locher, 77-99. Berlin: Mouton de Gruyter.

Matoesian, G. 2005. Struck by Speech Revisited: Embodied Stance in Jurisdictional Discourse. Journal of Sociolinguistics 9 (2): 167-193. doi:10.1111/j.1360-6441.2005.00289.x.

Micheli, R. 2008. L'analyse argumentative en diachronie: Le pathos dans les débats parlementaires sur l'abolition de la peine de mort. Argumentation et Analyse du Discours 1: $1-21$.

Neurauter-Kessels, M. 2013. Impoliteness in Cyberspace: Personally Abusive Reader Responses in Online News Media. Ph.D. Thesis, University of Zurich, Switzerland. Retrieved from http://opac.nebis.ch/ediss/20131752.pdf

Ochs, E., and B. Schieffelin. 1989. Language Has a Heart. Text 9 (1): 7-25.

Oster, U. 2012. Using corpus methodology for semantic and pragmatic analyses: What can corpora tell us about the linguistic expression of emotions? Cognitive Linguistics 21 (4): 727763.

Pavlenko, A. 2002. Emotions and the Body in Russian and English. Pragmatics and Cognition 10 (1/2): 207-241. doi:10.1075/pc.10.12.10pav.

Pepin, N. (ed.). 2008. Studies on Emotions in Social Interactions [Special Issue]. Bulletin Suisse de Linguistique Appliquée (VALS-ASLA) 88. Retrieved from http://doc.rero.ch/Im.php?url=1000,20,10,bulletin_vals_asla_2008_088.pdf

Pfänder, S., and E. Gülich. 2013. Zur interaktiven Konstitution von Empathie im Gesprächsverlauf. Ein Beitrag aus der Sicht der linguistischen Gesprächsforschung. In Grenzen der Empathie: Philosophische, psychologische und anthropologische Perspektiven, ed. T. Breyer, 433-458. München: Fink.

Planalp, S. 1998. Communicating Emotion in Everyday Life: Cues, Channels, and Processes. In Handbook of Communication and Emotion: Research, Theory, Applications, and Contexts, ed. P.A. Andersen and L.K. Guerrero, 29-48. San Diego: Academic Press.

-. 1999. Communicating Emotion: Social, Moral, and Cultural Processes. Cambridge, UK: Cambridge University Press.

Plutchik, R. 1962. The Emotions. Facts, Theories, and a New Model. New York: Random House.

-. 1980. Emotion. A Psychoevolutionary Synthesis. New York: Harper \& Row. 
-. 2003. Emotions and Life: Perspectives from Psychology, Biology, and Evolution. Washington, DC: American Psychological Association.

Powers, N., and C. Trevarthen. 2009. Voices of Shared Emotion and Meaning: Young Infants and their Mothers in Scotland and Japan. In Communicative Musicality. Exploring the Basis of Human Companionship, ed. S. Malloch and C. Trevarthen, 209-240. Oxford, UK: Oxford University Press.

Reber, E. 2012. Affectivity in Interaction. Sound Objects in English. Amsterdam: John Benjamins. Ruhi, Ş. 2007. Higher-Order Intentions and Self-Politeness in Evaluations of (im) Politeness: The Relevance of Compliment Responses. Australian Journal of Linguistics 27 (2): 107-145. doi:10.1080/07268600701522756.

-. 2009. Evoking Face in Self and Other-Presentation in Turkish. In Face, Communication and Social Interaction, ed. F. Bargiela-Chiappini and M. Haugh, 155-174. London: Equinox.

Ruhi, Ş., and H. Isik-Güler. 2007. Conceptualizing Face and Relational Work in (im)Politeness: Revelations from Politeness Lexemes and Idioms in Turkish. Journal of Pragmatics 39 (4): 681-711. doi:10.1016/j.pragma.2006.11.013.

Sacks, H. 1992. Lectures on Conversation. Volumes I \& II. Oxford, UK: Blackwell.

Scherer, K.R. 1984. On the Nature and Function of Emotion: A Component Process Approach. In Approaches to Emotion, ed. K.R. Scherer and P. Ekman, 293-317. Hillsdale: Lawrence Erlbaum.

Scherer, K.R., A. Shorr, and T. Johnstone, eds. 2001. Appraisal Processes in Emotion: Theory, Methods, Research. New York: Oxford University Press.

Schwarz-Friesel, M. 2007. Sprache und Emotion. Tübingen: Francke.

Spencer-Oatey, H. 2005. (Im)Politeness, Face and Perceptions of Rapport: Unpackaging their Bases and Interrelationships. Journal of Politeness Research 1 (1): 95-119. doi:10.1515/jplr.2005.1.1.95.

-. 2007. Theories of Identity and the Analysis of Face. Journal of Pragmatics 3 (4): 639-656. doi:10.1016/j.pragma.2006.12.004.

-. 2011. Conceptualising 'The Relational' in Pragmatics: Insights from Metapragmatic Emotion and (Im)politeness Comments. Journal of Pragmatics 4 (14): 3565-3578.

doi:10.1016/j.pragma.2011.08.009.

Streeck, J. 2009. Gesturecraft. The Manufacture of Meaning. Amsterdam: John Benjamins.

Trevarthen, C. 1999. Musicality and the Intrinsic Motive Pulse: Evidence from Human

Psychobiology and Infant Communication. Musicae Scientiae: 155-215. doi:10.1177/10298649000030S109.

-. 2002. Origins of Musical Identity: Evidence from Infancy for Musical Social Awareness. In Musical Identities, ed. R.A.R. MacDonald, D.J. Hargreaves, and D. Meill, 21-38. Oxford, UK: Oxford University Press.

Tronick, E.Z. 2005. Why Is Connection with Others So Critical? The Formation of Dyadic States of Consciousness: Coherence Governed Selection and the Cocreation of Meaning out of Messy Meaning Making. In Emotional Development, ed. J. Nadel and D. Muir, 293-315. Oxford, UK: Oxford University Press.

Turner, J.H. 2000. On the Origins of Human Emotions. A Sociological Enquiry into the Evolution of Human Affect. Stanford: Stanford University Press.

-. 2007. Human Emotions: A Sociological Theory. Oxford, UK: Routledge.

Turner, J.H., and J.E. Stets. 2005. The Sociology of Emotions. Cambridge, UK: Cambridge University Press. 
Wierzbicka, A. 1994. Emotion, Language, and Cultural Scripts. In Emotion and Culture, ed. S.

Kitayama and H.R. Markus, 133-196. Washington, DC: American Psychological Association. Wilce, J.E. 2009. Language and Emotion. Cambridge, UK: Cambridge University Press. 